\title{
9-AAA inhibits growth and induces apoptosis in human melanoma A375 and rat prostate adenocarcinoma AT-2 and Mat-LyLu cell lines but does not affect the growth and viability of normal fibroblasts
}

\author{
WŁODZIMIERZ KOROHODA, ANNA HAPEK, MONIKA PIETRZAK, \\ DAMIAN RYSZAWY and ZBIGNIEW MADEJA
}

\begin{abstract}
Department of Cell Biology, Faculty of Biophysics, Biochemistry and Biotechnology, Jagiellonian University, Krakow 30-387, Poland
\end{abstract}

Received July 19, 2015; Accepted June 8, 2016

DOI: $10.3892 / \mathrm{ol} .2016 .5201$

\begin{abstract}
The present study found that, similarly to 5-fluorouracil, low concentrations (1-10 $\mu \mathrm{M})$ of 9-aminoacridine (9-AAA) inhibited the growth of the two rat prostate cancer AT-2 and Mat-LyLu cell lines and the human melanoma A375 cell line. However, at the same concentrations, 9-AAA had no effect on the growth and apoptosis of normal human skin fibroblasts (HSFs). The differences between the cellular responses of the AT-2 and Mat-LyLu cell lines, which differ in malignancy, were found to be relatively small compared with the differences between normal HSFs and the cancer cell lines. Visible effects on the cell growth and survival of tumor cell lines were observed after 24-48 h of treatment with 9-AAA, and increased over time. The inhibition of cancer cell growth was found to be due to the gradually increasing number of cells dying by apoptosis, which was observed using two methods, direct counting and FlowSight analysis. Simultaneously, cell motile activity decreased to the same degree in cancer and normal cells within the first $8 \mathrm{~h}$ of incubation in the presence of 9-AAA. The results presented in the current study suggest that short-lasting tests for potential anticancer substances can be insufficient; which may result in cell type-dependent differences in the responses of cells to tested compounds that act with a delay being overlooked. The observed differences in responses between normal human fibroblasts and cancer cells to 9-AAA show the requirement
\end{abstract}

Correspondence to: Professor Zbigniew Madeja or Professor Włodzimierz Korohoda, Department of Cell Biology, Faculty of Biophysics, Biochemistry and Biotechnology, Jagiellonian University, 7 Gronostajowa, Krakow 30-387, Poland

E-mail: z.madeja@uj.edu.pl

E-mail: w.korohoda@uj.edu.pl

Key words: 9-aminoacridine, 5-fluorouracil, apoptosis, specific inhibition of cancer cell growth for additional studies to be performed simultaneously on differently reacting cancer and normal cells, to determine the molecular mechanisms responsible for these differences.

\section{Introduction}

In a previous study, low concentrations of 9-aminoacridine (9-AAA) were observed to effectively decrease the threshold of the direct current electric field strength required for cell electroporation, but did not affect normal and cancer cell viability when applied for 2-3 h (1). Nevertheless, when normal and cancer cells were left to grow in the presence of 9-AAA for 2-5 days, the rat prostate cancer cells and human melanoma cells died, whereas normal human skin fibroblasts (HSFs) continued to grow (1).

The drug 9-AAA and its derivatives have been studied since the 1960's, and have been shown to exhibit a broad spectrum of biological activity. At the beginning of the 20th century, these compounds were applied in medicine against protozoan infections and diseases caused by bacteria and yeasts (2-4). In the second half of the century, studies recognized the mutagenic activity of 9-AAA and its derivatives, in particular in bacteria and yeasts, and have since been extensively studied (5-8). The biological activity of the compounds was previously observed to be associated, among other effects, with their capacity to intercalate into DNA (9). 9-AAA has also been found to be useful in research concerning ion channels in biological membranes (10-12) and has been shown to improve the banding patterns of human and plant chromosomes for image analysis (13). Furthermore, 9-AAA has been applied for analysis of the surface electric potential on surfaces of cells, protoplasts and liposomes (14-17).

A previous study reported that 9-AAA inhibits the growth of animal cells and demonstrates anticancer activity in vivo (18). In 1969, Mendecki et al reported that 9-AAA inhibited the synthesis of RNA in regenerating rat liver cells grown in vitro (19). In general, 9-AAA is applied for a short time at relatively high concentrations $(>10 \mu \mathrm{M})$, and the effects are observed for a short time (usually $<48 \mathrm{~h}$ ). In the majority 
of modern molecular studies concerning the effects of 9-AAA on cancer cells, the effects of 9-AAA were followed for 1-2 days (19-25).

Certain studies have shown that cell responses to external factors are often delayed and become visible after a few days $(26,27)$. In contrast to the majority of reported research, the present study therefore examined the effects of 9-AAA on the growth of 3 cancer cell lines ( 2 prostate cancer cell lines differing in malignancy and 1 human malignant melanoma) and on normal HSFs in cell culture. The tested 9-AAA was present continuously in the cell culture medium at concentrations that did not significantly affect the viability of cells during the first $8 \mathrm{~h}$ of its application. The effects of 9-AAA were compared with the 5-fluorouracil (5-FU), a known anticancer drug that is commonly used for cancer therapy in clinics $(28,29)$.

\section{Materials and methods}

Cell cultures. All experiments were performed with normal HSFs and 3 cancer cell lines, including human melanoma A375 cells and 2 rat prostate cancer cell lines from the Dunning R-3327 system: Highly malignant Mat-LyLu and moderately malignant AT-2 (1,30,31). The cells were plated in 6-well Falcon culture plates at a density of 20000 cells per well, $24 \mathrm{~h}$ prior to the addition of 9-AAA or 5-FU (Sigma-Aldrich, St. Louis, MO, USA). HSFs and A375 cells were grown in Dulbecco's modified Eagle's medium (DMEM) with a high glucose concentration (4,500 mg/l; Sigma-Aldrich), and rat prostate adenocarcinoma AT-2 and Mat-LyLu cell lines were grown in RPMI-1640 medium (Lonza Group, Basel, Switzerland). The two media were supplemented with $10 \%$ heat inactivated fetal calf serum (FCS; Gibco; Thermo Fisher Scientific, Inc., Waltham, MA, USA) and with a $1 \%$ antibiotics solution at final concentration of 100 international units penicillin, $100 \mu \mathrm{g}$ streptomycin and $0.25 \mu \mathrm{g}$ amphotericin per $\mathrm{ml}$ (Gibco; Thermo Fisher Scientific, Inc.). The cells were propagated at $37^{\circ} \mathrm{C}$ in humid air with $5 \% \mathrm{CO}_{2}$. The tested inhibitors, 9-AAA and 5-FU, were dissolved in cell culture medium and applied in concentrations in the range 1-30 $\mu \mathrm{M}$, as shown in the Results section. Cells cultured in DMEM alone were used as the control. To estimate the effect of the tested compounds on cell growth, the cells were harvested after 24, 48, 72 and $96 \mathrm{~h}$ by trypsinization, washed in phosphate-buffered saline (PBS) by centrifugation at $400 \mathrm{x} g$ and counted using a Bürker haemocytometer.

Cell motile activity. Cell motile activity was examined by recording the movements of individual cells and analyzing cell trajectories, as described in detail in previous studies (30-32). The results are presented in the form of circular diagrams, correlation diagrams and the results of calculations.

Cell viability. Cell viability was tested using trypan blue exclusion tests as described previously (32), and in each sample at least 300 cells were analyzed. The type of cell death, apoptosis or necrosis, was examined with two complementary methods.

An analysis of the apoptotic/necrotic cell death of AT-2 cells, Mat-LyLu cells and HSFs growing in the control media or in the presence of 1,5 or $10 \mu \mathrm{M} 9$-AAA or 5,10 or $15 \mu \mathrm{M} 5$-FU was performed following 24,48 or $72 \mathrm{~h}$ of cell culture using two methods. For the first method, the cells were harvested by trypsinization, washed in PBS and stained with propidium iodide (50 $\mu \mathrm{g} / \mathrm{ml}$; Sigma-Aldrich). The cells were analyzed with a FlowSight image flow cytometer and Ideas 5.0 software (Amnis Corporation, Seattle, WA, USA). For each sample, images of 10,000 single cells were analyzed at 488 and $785 \mathrm{~nm}$ light wavelength using three channels, as described previously (33). For the second method, the cells were fixed in $3.5 \%$ formaldehyde for $20 \mathrm{~min}$. The cells were then stained in $0.5 \mathrm{ml}$ Hoechst 33342 in PBS $(1 \mu \mathrm{g} / \mathrm{ml})$, prior to direct observation under a fluorescence microscope (Leica DMI6000B, type AF7000; Leica Microsystems $\mathrm{GmbH}$, Wetzlar, Germany) at a light excitation wavelength of $352 \mathrm{~nm}$. For each sample, $>250$ cells were observed and analyzed. The number of apoptotic cells with fragmented nuclei was counted.

Statistical analysis. All experiments were conducted in triplicate, giving similar results, and data are presented as the mean values. For analysis of cell motility, a Mann-Whitney test was used and results were considered significant if $\mathrm{P}<0.05(\mathrm{n}=50)$. For other analyses, a two-sample independent Student's t-test was used and $\mathrm{P}<0.05$ was considered to indicate a statistically significant difference.

\section{Results}

Cell type-specific effects of 5-FU and 9-AAA upon growth of cancer and normal cells in vitro. In the first series of experiments, the effect of the continuous presence of 9-AAA in cell culture medium, at concentrations of 1-20 $\mu \mathrm{M}$, on cell proliferation was examined. The effect of 9-AAA on cell proliferation was compared with the effect of 5-FU, a known and commonly used cytostatic drug in clinical oncology, which was applied at concentrations of 5-30 $\mu \mathrm{M}$. In preliminary experiments (data not shown), 9-AAA and 5-FU, in the examined range of concentrations, did not show acute toxicity, and $>90 \%$ of all tested cell types survived for 4 and $8 \mathrm{~h}$ of incubation in their presence, as tested with the trypan blue exclusion test. The response to these two substances was tested on HSFs, as an example of normal cells, and on 3 neoplastic, established cell lines, including the human melanoma A375, rat prostate highly metastatic adenocarcinama Mat-LyLu and moderately malignant rat prostate AT-2 cell lines (Fig. 1). The highly cell type-specific effects on cell proliferation were recorded.

The examined substances, 5-FU (Fig. 1A-C) and 9-AAA (Fig. 1D-G), in the highest tested concentrations (30 and $20 \mu \mathrm{M}$, respectively) had no statistically significant effect upon growth of HSFs. At the concentrations of 5, 10, 15 and $30 \mu \mathrm{M}, 5-\mathrm{FU}$ inhibited proliferation in the two tested rat prostate adenocarcinoma cell lines (Fig. 1B and C; AT-2 $\mathrm{P}=0.017$, $\mathrm{P}=0.016, \mathrm{P}=0.016, \mathrm{P}=0.015$; MAT-LyLu $\mathrm{P}=0.031, \mathrm{P}=0.029$, $\mathrm{P}=0.027, \mathrm{P}=0.025$, respectively). At the concentrations of 1 , 5, 10 and $15 \mu \mathrm{M}, 9-\mathrm{AAA}$ inhibited cell growth in the tested two rat prostate adenocarcinoma cell lines differing in malignancy (Fig. 1E and F; AT-2 $\mathrm{P}=0.016, \mathrm{P}=0.01, \mathrm{P}=0.01, \mathrm{P}=0.01$; MAT-LyLu $\mathrm{P}=0.018, \mathrm{P}=0.01, \mathrm{P}=0.01, \mathrm{P}=0.01$, respectively). At 

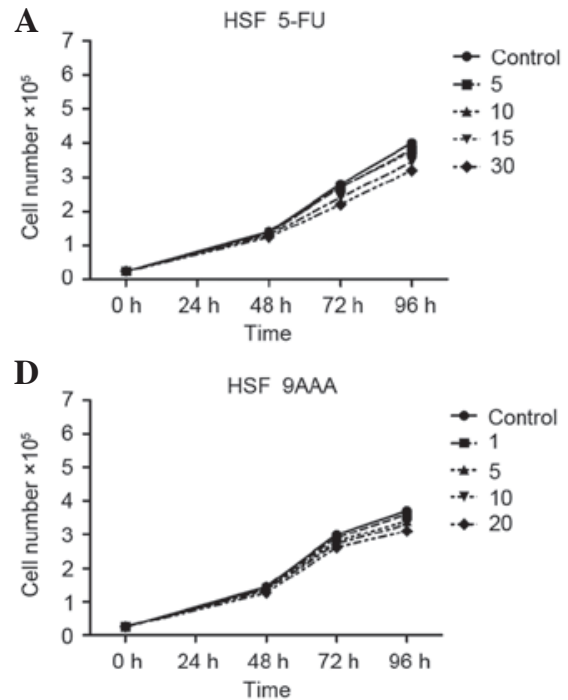

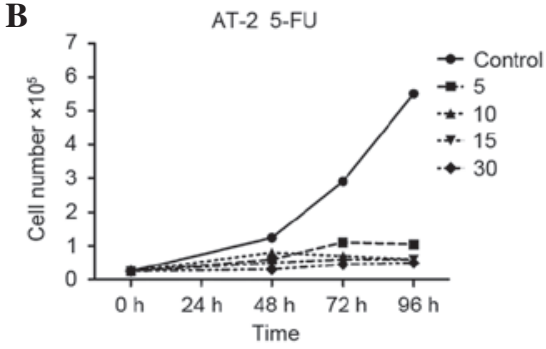

$\mathbf{E}$

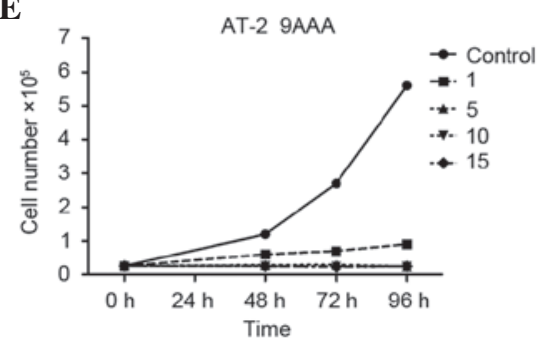

G

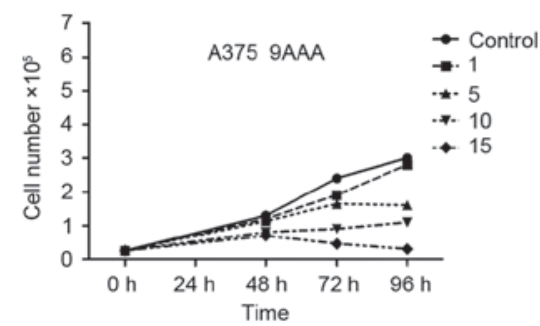

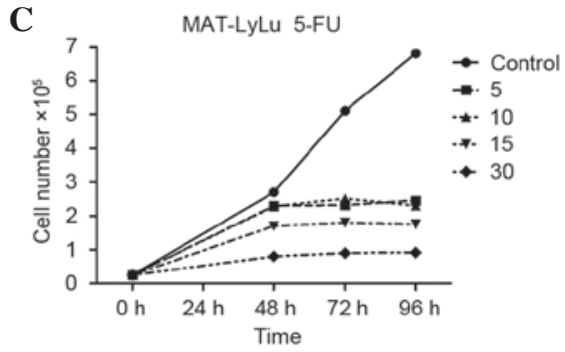

F

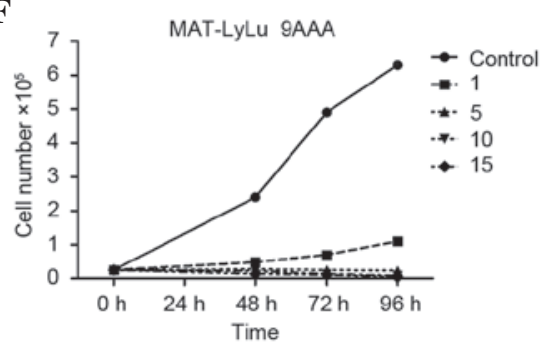

Figure 1. Effects of (A-C) 9-AAA and (D-G) 5-FU on the growth of various cells: (A and D) HSFs; rat prostate adenocarcinoma (B and E) AT-2 and (C and F) Mat-LyLu cell lines; and (G) human melanoma A375 cell line. Abscissa, time of cell growth (h); ordinate, cell number per well (in 6-well culture flasks). 9-AAA, 9-aminoacridine; 5-FU, 5-fluorouracil; HSF, human skin fibroblast.

Hoechst

A

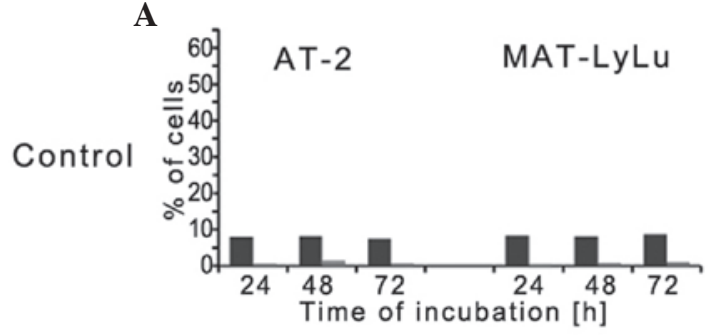

C

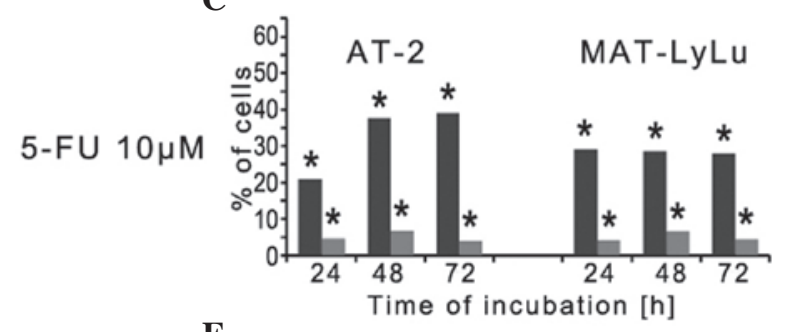

$\mathbf{E}$

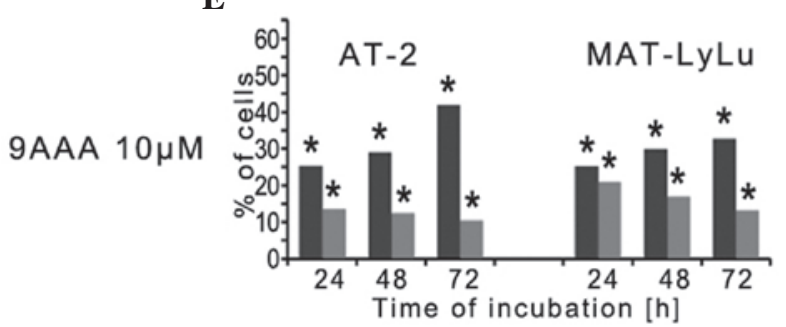

Flowsight

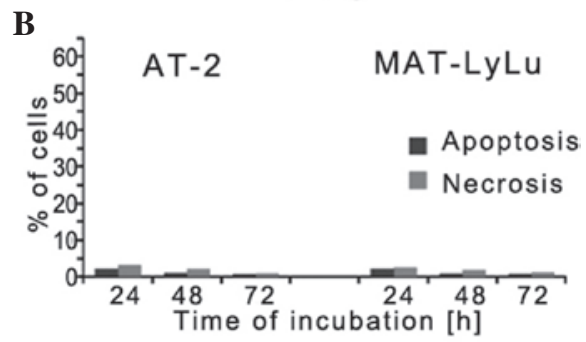

D

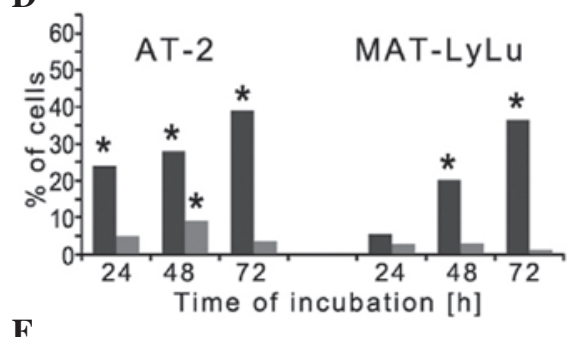

F

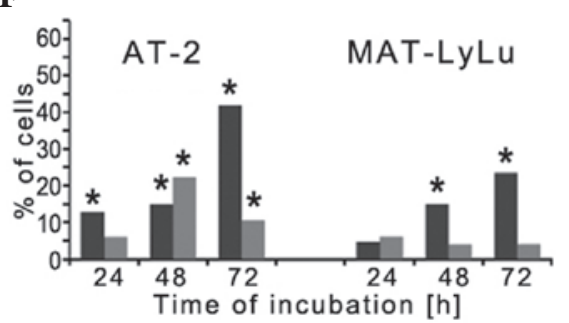

Figure 2. Effects of $10 \mu \mathrm{M}$ 5-FU or 9-AAA treatment on AT-2 and Mat-LyLu cell death by apoptosis and necrosis, analyzed with two methods. (A and B) Control (no treatment); (C and D) $10 \mu \mathrm{M}$ 5-FU treatment; (E and F) $10 \mu \mathrm{M}$ 9-AAA treatment. Results were assessed by (A, C and E) direct observation of cells under fluorescence microscope after Hoechst 33342 staining, and (B, D and F) single cell analysis with FlowSight flow cytometry of propidium iodide-stained cells. 5-FU, 5-fluorouracil; 9-AAA, 9-aminoacridine. Data are expressed as mean values and were analyzed with a two sample independent Student's $t$-test; " $\mathrm{P}<0.05$ vs. control. 

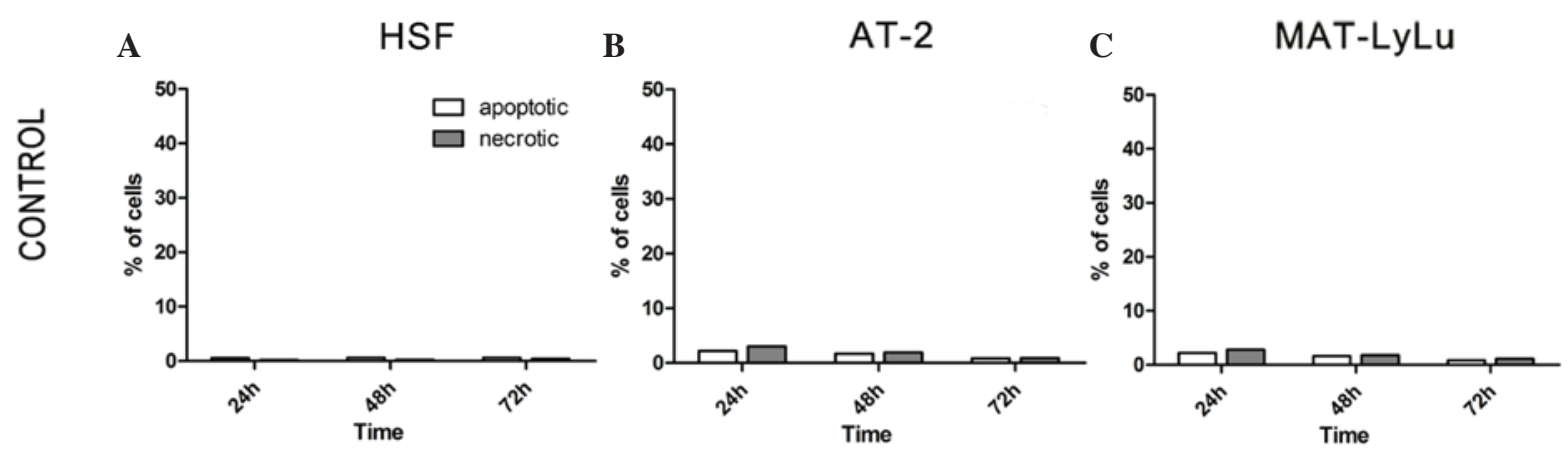

$$
\text { D }
$$

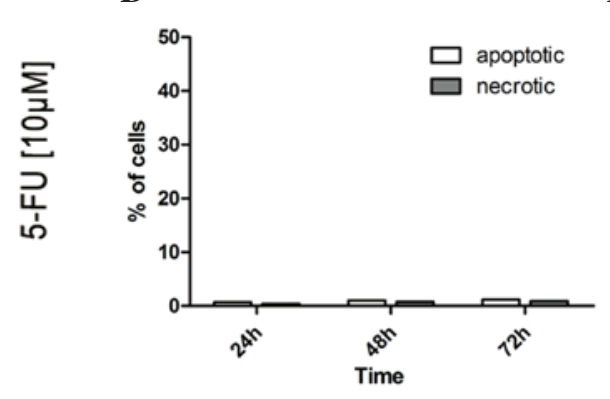

G

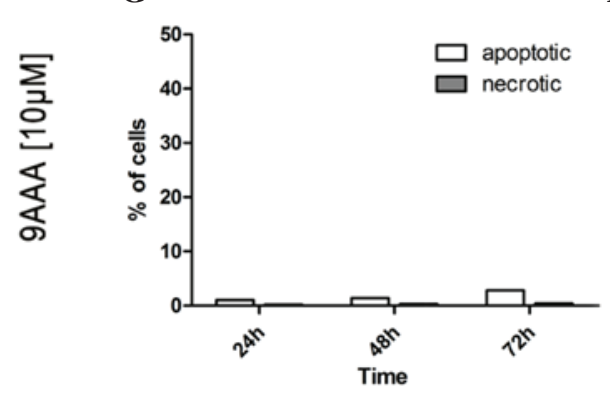

E

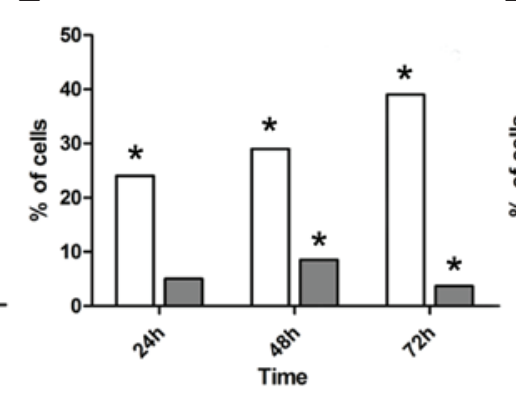

H

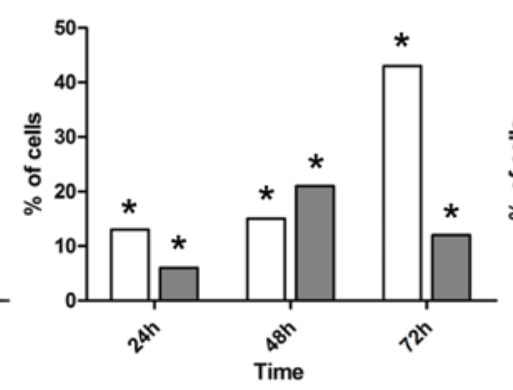

F

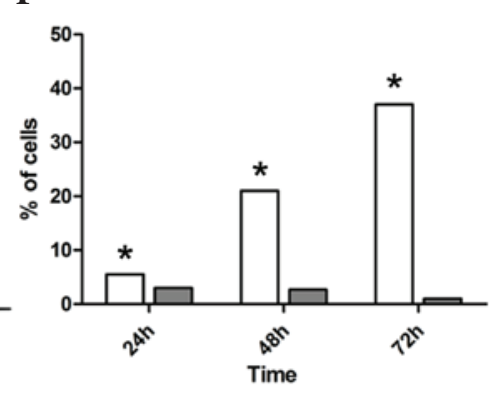

I

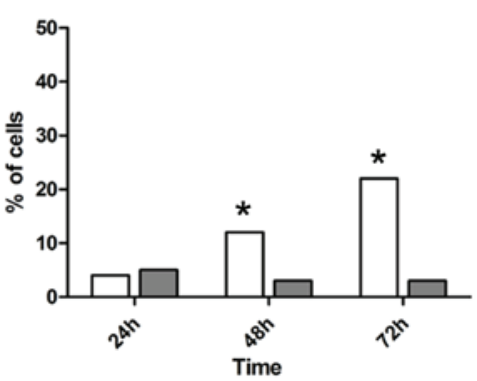

Figure 3. Image FlowSight analysis of (A, D and G) HSF, (B, E and H) AT-2 and (C, F and I) Mat-LyLu cell death by apoptosis and necrosis when growing in control medium or the medium supplemented with 5-FU $(10 \mu \mathrm{M})$ and 9-AAA $(10 \mu \mathrm{M})$. HSF, human skin fibroblast; 5-FU, 5-fluorouracil; 9-AAA, 9-aminoacridine. Data are expressed as mean values and were analyzed with a two sample independent Student's t-test; " $\mathrm{P}<0.05$ vs. control.

the lowest tested concentration, $1 \mu \mathrm{M}$, 9-AAA fully inhibited the growth of both rat prostate cancer cell lines $(\mathrm{P}=0.01)$, but not human melanoma cells. In the A375 melanoma cell culture, 9-AAA inhibited the growth of cells with a delay, when applied at the following concentrations: 5,10 or $15 \mu \mathrm{M}$ (Fig. 1G; $\mathrm{P}=0.034, \mathrm{P}=0.031, \mathrm{P}=0.019)$. Notably, the inhibition of neoplastic cell growth caused by 9-AAA and 5-FU was not immediate. Independently, whether the substances were added at the start of the culture or on the second day, the growth inhibition only became marked after 24-48 $\mathrm{h}$ incubation of cells in the presence of 5-FU or 9-AAA.

Pro-apoptotic activity of 5-FU and 9-AAA in cancer cells, but not in normal HSFs. The subsequent experiments aimed to examine whether the growth inhibition of the tested cancer cells by 9-AAA is associated with the specific killing of cells by apoptosis or by necrosis. Two methods were applied: i) Cells stained with Hoechst 33342 were directly counted under a microscope to observe the morphology of nuclei in apoptotic cells and necrotic cells. This method permits observation of individual single cells, and therefore is limited to observation of several hundred cells in a sample. ii) In parallel, the samples from the same cell culture were analyzed with the modern method using FlowSight, which analyzes thousands of cells (33). The results obtained using the two methods combined yielded well-corresponding results (Fig. 2).

FlowSight analysis was used to examine the number of cells dying by apoptosis and necrosis in the prescence or absence of 5-FU or 9-AAA (Fig. 3). In HSFs, in the absence of the tested substances, the number of dying cells did not exceed $0.5 \%$ (Fig. 3A). In the presence of $10 \mu \mathrm{M}$ 9-AAA and after 3 days of culture, the number of dying cells increased, but remained $<3 \%$, and more cells died by apoptosis compared with necrosis (Fig. 3D and G). By contrast, the cells of the 2 rat prostate cancer AT-2 and MAT-LyLu cells began to die after growing for $24 \mathrm{~h}$ in the presence of the tested inhibitors (Fig. 3B, C, E, F, H and I; P=0.01). In the rat prostate cancer AT-2 and Mat-LyLu cell lines, which differ in malignancy, the observed effects of each inhibitor were almost the same. The 
A

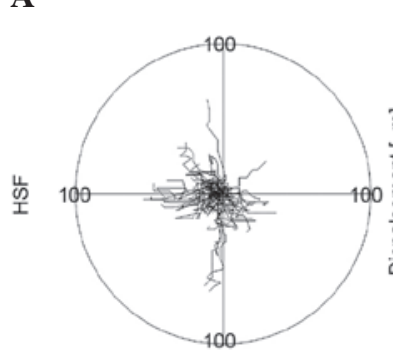

Control

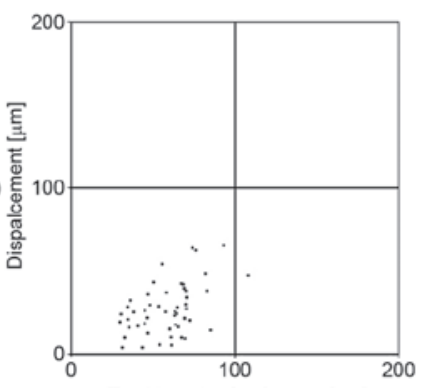

C
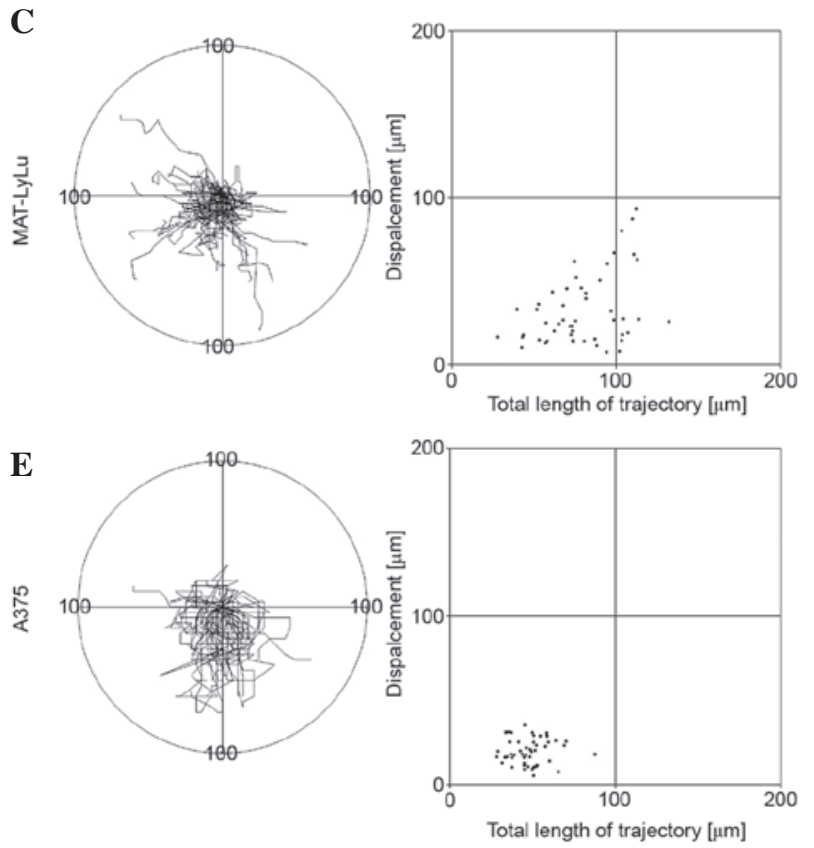

B

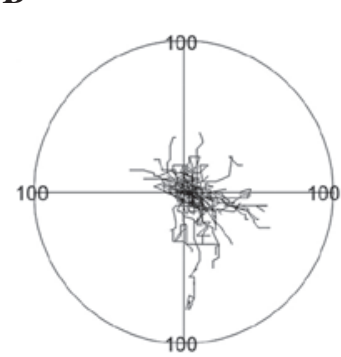

$20 \mu \mathrm{m}$ 9-AAA

D
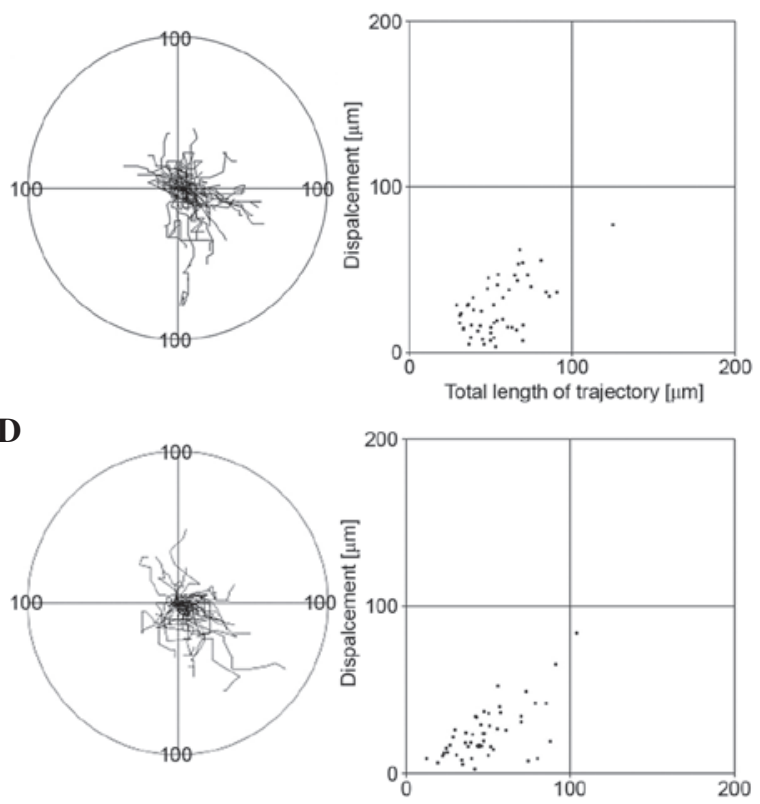

F

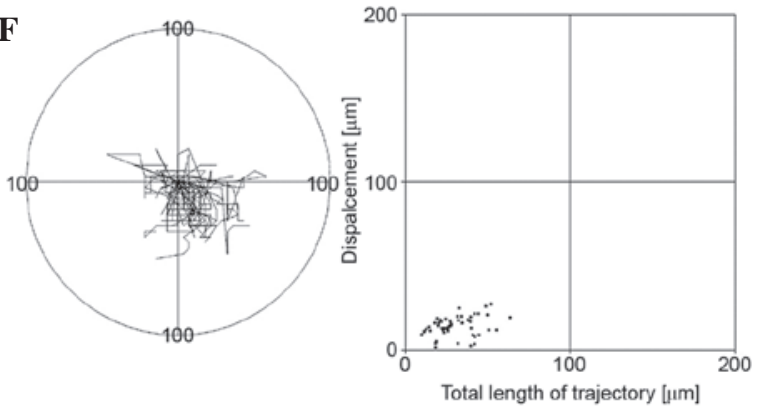

Figure 4. Effect of the medium supplementation with $20 \mu \mathrm{M}$ 9-AAA on the motile activity of HSFs, rat prostate cancer Mat-LyLu cells and human melanoma A375 cells. The trajectories of HSF migrating (A) under control conditions or (B) in the presence of 20 $\mu$ M 9-AAA, Mat-LyLu migrating (C) under control conditions or (D) in the presence of $20 \mu \mathrm{M}$ 9-AAA and A375 cells migrating (E) under control conditions (F) or in the presence of $20 \mu \mathrm{M} 9-\mathrm{AAA}$ are presented in the circular diagrams and in the form of scatter correlation diagrams. Please notice similar decrease in the length of cell trajectory, final translocation and speed of movement in normal and cancer cells. 9-AAA, 9-aminoacridine; HSF, human skin fibroblast.

numbers of dying cells increased with time and after 3 days of cell culture reached $>40 \%$. The proportion of cells dying by apoptosis was much greater compared with the cells dying by necrosis. AT- 2 cells were found to be slightly more sensitive to the 9-AAA and 5-FU compared with Mat-LyLu. In the presence of inhibitors, despite the great proportion of dying cells, dividing cells were observed via direct observation after staining with Hoechst, in particular, when the inhibitors were applied at the $5 \mu \mathrm{M}$ concentration.

Lack of differential effects of 5-FU and 9-AAA on cancer and normal cell movement. Since cancer cell malignancy and the capacity of cells to metastasize is usually correlated with cell motile activity, the present study examined the effect of 9-AAA on the migration of 3 cell lines, including normal HSFs, rat prostate malignant cancer Mat-LyLu and human melanoma A375 cells. In previous experiments, a single-cell approach and computer-aided methods were applied for recording and analyzing cell movement trajectories in the absence and in the presence of 9-AAA $(30,33)$. Cell movement was recorded $24 \mathrm{~h}$ after cells were seeded.
The control experiments were carried out in cell culture medium. The effects of 9-AAA on cell movement were examined at a concentration of $20 \mu \mathrm{M}$, the highest examined in experiments concerning cell growth. The results of the cell movement records in the absence or in the presence of the highest concentration tested are shown in Fig. 4. Even at the highest concentration of 9-AAA, which inhibited the growth of human melanoma cells and rat prostate malignant cancer Mat-LyLu cell line (but not the growth of HSFs), the 9-AAA had no statistically significant different effect on the speed of cell movement/length of cell trajectories, the shape of the cell trajectories, or the cell turning frequency of the normal HSF or 2 cancer cell lines (Fig. 4). In all 3 cell lines the presence of 9-AAA in cell medium similarly affected the speed of cell movement and the length of cell trajectories.

\section{Discussion}

The results presented in the current study show that 9-AAA and $5-\mathrm{FU}$, when present at low concentrations (1 or $5 \mu \mathrm{M}$, respectively) in cell culture medium, efficiently inhibited the 
growth of 2 rat prostate cancer cell lines, AT-2 and Mat-LyLu, but had no influence on the viability and growth of HSFs. Human melanoma A375 cells were inhibited at a concentration of 5, 10 and $15 \mu \mathrm{M}$ 9-AAA. Even greater concentrations of these substances $(20$ and $30 \mu \mathrm{M})$ did not inhibit growth of the normal HSFs.

The growth inhibition in the examined cancer cell lines was caused by 9-AAA and 5-FU at concentrations that did not affect the cell viability if applied for $8 \mathrm{~h}$. The microscopic observation of cancer cells, for which proliferation was retarded or inhibited after 3 days of cell culture in the presence of 9-AAA or 5-FU, showed dividing cells among cells undergoing death by necrosis or by apoptosis (formation of apoptotic bodies). One can expect that, in heterogeneous cell populations such as populations of cancer cell lines $(32,33)$, the cells that proliferate are present alongside cells that die by apoptosis or necrosis. The present study demonstrated that the inhibition of increased cell numbers in cancer cell cultures in the presence of 5-FU and 9-AAA resulted from an increased proportion of dying to proliferating cells over time.

Therefore, the capacity of 9-AAA and 5-FU to induce apoptosis was compared in normal HSFs and in rat prostate cell lines. The application of two methods that permitted the discrimination of cells dying by apoptosis and necrosis yielded the same results. Both 9-AAA and 5-FU induced an increasing number of cells dying by apoptosis in cancer cell populations, but did not markedly change the proportion of apoptotic cells in normal HSF cultures.

Numerous research concerning the effects of 9-AAA on cancer cells in vitro have been reported, however, effects were observed within 3-8 h of 9-AAA administration. The tested substances were applied for a short time and results were followed for a few hours, usually in one type of cancer cell. Nevertheless, among the numerous reports concerning the impact of 9-AAA and its derivatives (for example quinacrine) on cancer cells, certain studies appear to have demonstrated similar results compared with the findings indicated in the present study.

Gurova et al (34) reported that 9-AAA pro-apoptotic activity is associated with inhibition of the transition of cells from $\mathrm{G} 1$ phase to the $\mathrm{S}$ phase of the cell cycle. This may partly explain why the inhibition of cancer cell proliferation in the presence of low concentrations of 9-AAA is observed with delay, only after 24-48 h. In asynchronous cell culture, only a small fraction of cells may be susceptible to the inhibitory activity of the inhibitor in a short window of time. However, there is a lack of studies on this topic of research, which may explain why there are such large differences in the cellular response to low concentrations of 9-AAA or 5-FU between the tested cancer cell lines and normal HSFs. These differences may be associated with the observations made by Wang et al (22), Gurova et al (34) and Guo et al (35), regarding the effects of 9-AAA on proteins, including tumor protein 53, $\mathrm{Bcl} 2$ associated $\mathrm{X}$ protein and transcription factor nuclear factor- $\kappa \mathrm{B}$, and/or by Teitelbaum et al (36) on topoisomerase II and topoisomerase I (37). Expression of these proteins usually differs in normal and cancer cells (34). However, the explanation of the results observed for cancer cells in vitro and in vivo, reported by Etchison et al (25) and Guo et al (35), requires supplementation by results from parallel, simultaneous experiments involving cancer and normal cells, differing in their responses to the tested drugs.

The difference in reactions among various cells could also be partly due to the differences in electrochemical properties of the surface of cancer and normal cells (38-42). As a cationic substance, 9-AAA may more strongly affect the cancer cells, whose surface is more negatively electrically charged compared with the surface of normal cells, as the effect of 9-AAA on cell membranes was previously found to depend upon the negative electric charging of cell surfaces and liposomes $(14,16,17,43)$. This phenomenon may result in varying responses of cells, differing in membrane electric properties. In addition, 9-AAA was reported to affect electric charges on cell surface and ion fluxes across membrane channels (8-12,14-17). This may modify the penetration of 9-AAA into cells or an operation of signaling pathways and interactions among cells. Therefore, the differences between the responses of cancer and normal cells do not appear to result solely and primarily from the often investigated intercalation of 9-AAA to DNA and its mutagenic activity.

It is well documented that the capacity of cancer cells to metastasize correlates with their motile activity $(30,44,45)$. The results of the current demonstrated that 9-AAA and 5-FU similarly affected the movement of cancer and normal cells, at least within the first few hours of its application to the cells. This shows that the agents that can affect cancer cell malignancy and the capacity of cells to metastasize, i.e. influence cell motile behavior, are not necessarily the same agents that can result in the inhibition of cell growth, in particular if they induce cell death by apoptosis.

Teitelbaum et al (36) reported that 9-AAA derivatives in micromolar concentration can be efficient against mouse glioblastoma, and Etchison et al (25) suggested that the 9-AAA derivatives can be effective against small cell lung cancer. Overall, these observations suggest that 9-AAA and its derivatives may be promising targets for the chemotherapy of types of cancer that are considered to resistant to the majority of the presently applied anticancer drugs $(25,36,46)$.

In conclusion, the results of the present study, which regards the effectiveness of specific cancer cell growth inhibition by 5-FU and 9-AAA, indicate the requirement for additional studies on the molecular mechanisms responsible for the varied responses of normal and cancer cells to 9-AAA and its derivatives, and suggest that short term cytotoxicity evaluation can lead to potential anticancer compounds being overlooked. The results presented show that 9-AAA at low concentrations specifically inhibits growth and induces apoptosis in human melanoma A375 cells and 2 rat prostate cancer cells lines, but has no effect on the survival and growth of HSFs in tissue culture.

\section{Acknowledgements}

The present study was financially supported by the Polish National Science Centre (grant no., 2012/07/B/NZ3/02909). The Faculty of Biochemistry, Biophysics and Biotechnology of Jagiellonian University is also a partner of the Leading National Research Center, supported by the Ministry of Science and Higher Education. 


\section{References}

1. Grys M, Madeja Z and Korohoda W: Decreasing the thresholds for electroporation by sensitizing cells with local cationic anesthetics and substances that decrease the surface negative electric charge. Cell Mol Biol Lett 19: 65-76, 2014.

2. Wainwright M: Acridine-a neglected antibacterial chromophore. J Antimicrob Chemother 47: 1-13, 2001.

3. Sebestic J, Hlavácek J and Stibor I: A role of the 9-aminoacridines and their conjugates in a life science. Curr Protein Pept Sci 8: 471-483, 2007.

4. Valdés A: Acridine and acridinones: Old and new structures with antimalarial activity. Open Med Chem J 5: 11-20, 2011.

5. Kopsidas G and MacPhee D: Glucose inhibition of mutagenesis by 9-aminoacridine in Salmonella typhimurium. Mutat Res 285 101-108, 1993

6. Kopsidas G and MacPhee D: Frameshift mutagenesis by 9-aminoacridine: Antimutagenic effects of adenosine compounds. Mutat Res 352: 135-142, 1996

7. Acharya N, Abu-Nasr N, Kawaguchi G, Imai M and Yamamoto K: Frameshift mutations produced by 9-aminoacridine in wild-type, uvrA and recA strains of Escherichia coli; specificity within a hotspot. J Radiat Res 48: 361-368, 2007.

8. Galluce M, Agar G, Aslan A, Karadayi M, Bozari S and Orhan F: Protective effects of methanol extracts from Cladonia rangiformis and Umbilicaria vellea against known mutagens sodium azide and 9-aminoacridine. Toxicol Ind Health 27 675-682, 2011

9. Hoffmann GR, Laterza AM, Sylvia KE and Tartaglione JP Potentation of the mutagenicity and recombinagenicity of bleomycin in yeast by unconventional intercalating agents. Environ Mol Mutagen 52: 130-144, 2011.

10. Koschelev SG and Khodorov BI: Blockade of open NMDA channel by tetrabutylammonium, 9-aminoacridine and tacrine prevents channels closing and desensitization. Biologicheskie Membrany 9: 93-110, 1995.

11. Kim KH, Gmiro VE, Tikhonov DB and Magazanik LG: Mechanism of blockade of glutamate receptor ionic channels: Paradox of 9-aminoacridine. Biochemistry (Moscow) Supplement Series A: Membrane and Cell Biology 1: 88-95, 2007.

12. Barygin OI, Luchkina NV, Gmiro VE and Tikhonov DB Different mechanisms of the 9-aminoacridine block of NMDA-and AMPA-receptor ion channels. Biologicheskie Membrany 26: 280-286, 2009.

13. Muravenko OV, Amosova AV, Samatadze TE, Popov KV, Poletaev AI and Zelenin AV: 9-aminoacridine: An efficient reagent to improve human and plant chromosome banding patterns and to standardize chromosome image analysis. Cytometry A 51: 52-57, 2003

14. Theuvenet AP, Van De Wijngaard WM, Van De Rijke JW and Borst-Pauwels GW: Application of 9-aminoacridine as a probe of the surface potential experienced by cation transporters in the plasma membrane of yeast cells. Biochim Biophys Acta 775: $161-168,1984$

15. Ivanov AG and DiCosmo F: Microelectrophoretic and 9-aminoacridine fluorescence study of the surface electrical properties of suspension cultured Catharanthus roseus cells and isolated protoplasts: Effects of abscinic acid treatment. Plant Cel Physiol 36: 709-715, 1995.

16. Gage RA, Theuvenet AP and Borst-Pauwels GW: Effect of plasmolysis upon monovalent cation uptake, 9-aminoacridine binding and the zeta potential of yeast cells. Biochim Biophys Acta 854: 77-83, 1986.

17. Aharon D, Weitman H and Ehrenberg B: The effect of liposomes surface electric potential on the uptake of hematoporphyrin. Biochim Biophys Acta 1808: 2031-2035, 2011.

18. Radzikowski C, Ledóchowski Z, Ledóchowski A, Wrzołek S, Hrabowska M and Konopa J: The evaluation of antitumor properties of acridine derivatives on the basis of the results from some in vivo and in vitro tests. Arch Immunol Ther Exp (Warsz) 15: 126-128, 1967

19. Mendecki J, Więckowska Z and Chorąży M: Inhibition of RNA synthesis by 9 -aminoacridine in regenerating rat liver and cell culture. Acta Biochim Pol 16: 253-262, 1969.

20. Rehn C and Pindur U: Molecular modeling of intercalation complexes of antitumor active 9-aminoacridine and a $[d, e]$-anellated isoquinoline derivative with base paired deoxytetranucleotides. Monatshefte für Chemie 127: 645-658, 1996
21. Murza A, Sánchez-Cortéz S, Garcia-Ramos JV, Guisan JM, Alfonso C and Rivas G: Interaction of the antitumor drug 9-aminoacridine with guanidinobenzoatase studied by spectroscopic methods: A possible tumor marker probe based on the fluorescence exciplex emission. Biochemistry 39: 10557-10565, 2000.

22. Temple MD, Recabarren P, McFadyen WD, Holmes RJ, Denny WA and Murray V: The interaction of DNA-targeted 9-aminoacridine-4-carboxamide platinum complexes with DNA in intact human cells. Biochim Biophys Acta 1574: 223-230, 2002.

23. Kumar P, Kumar R and Prasad DN: Synthesis and biological evaluation of new 9-aminoacridine-4-carboxamide derivatives as anticancer agents: 1st Cancer Update. Arab J Chem 6: 59-65, 2013.

24. Wang WG, Ho WC, Dicker DT, MacKinnon C, Winkler JD, Marmorstein R and El-Deiry WS: Acridine derivatives activate p53 and induce tumor cell death through Bax. Cancer Biol Ther 4: 893-898, 2005.

25. Ryan E, Blake AJ, Benoit A, David MF and Robert AK: Efficacy of substituted 9-aminoacridine derivatives in small cell lung cancer. Invest New Drugs 31: 285-292, 2013.

26. Reiss K and Korohoda W: The formation of myotubes in cultures of chick embryo myogenic cells in serum-free medium is induced by the insulin pulse treatment. Folia Histochem Cytobiol 26: 133-141, 1988.

27. Reiss K, Kajstura J and Korohoda W: The insulin signal initiating cellular differentiation is preserved by chick embryo myoblasts incubated at $2^{\circ} \mathrm{C}$. Europ J Cell Biol 53: 42-47, 1990.

28. Longley DB, Harkin DP and Johnston PG: 5-fluorouracil: Mechanisms of action and clinical strategies. Nat Rev Cancer 3: 330-338, 2003

29. Raghunathan K and Priest DG: Modulation of fluorouracil antitumor activity by folic acid in a murine model system. Biochem Pharmacol 58: 835-839, 1999.

30. Djamgoz MBA, Mycielska M, Madeja Z, Fraser SP and Korohoda W: Directional movement of rat prostate cancer cells in direct-current electric field. Involvement of voltagegated $\mathrm{Na}^{+}$ channel activity. J Cell Sci 114: 2697-2705, 2001.

31. Waligórska A, Wianecka-Skoczeń M, Nowak P and Korohoda W: Some difficulties in research into cell motile activity under isotropic conditions. Folia Biol (Kraków) 55: 9-16, 2007.

32. Musialik E, Ryszawy D, Madeja Z and Korohoda W: Morpho-physiological heterogeneity of cells within two rat prostate carcinoma cell lines AT-2 and MAT-LyLu differing in the degree of malignancy observed by cell cloning and the effects of caffeine, theophylline and papaverine upon a proportion of the clones. Oncol Rep 29: 1789-1796, 2013.

33. Ryszawy D, Sarna M, Rak M, Szpak K, Kedracka-Krok S, Michalik M, Siedlar M, Zuba-Surma E, Burda K, Korohoda W, et al: Functional links between Snail-1 and $\mathrm{Cx} 43$ account for the recruitment of $\mathrm{Cx} 43$-positive cells into the invasive front of prostate cancer. Carcinogenesis 35: 1920-1930, 2014

34. Gurova KV, Hill JE, Guo C, Prokvolit A, Burdelya LG, Samoylova E, Khodyakova AV, Ganapathi R, Ganapathi M, Tararova ND, et al: Small molecules that reactivate 553 in renal cell carcinoma reveal a NF-kappaB-dependent mechanism of p53 suppression in tumors. Proc Natl Acad Sci USA 102: 17448-17453, 2005

35. Guo C, Gasparian AV, Zhuang Z, Bosykh DA, Komar AA, Gudkov AV and Gurova KV: 9-aminoacridine-based anticancer drugs target the PI3K/AKT/mTOR, NF-kappaB and p53 pathways. Oncogene 28: 1151-1161, 2009.

36. Teitelbaum AM, Gallardo JI, Bedi J, Giri R, Renoit AR, Olin MR, Morizio KM, Ohlfest JR, Remmel RP and Ferguson DM: 9-Amino acridine pharmacokinetics, brain distribution and in vitro/in vivo efficacy against malignant glioma. Cancer Chemother Pharmacol 69: 1519-1527, 2012

37. Galvez-Peralta M, Hackbarth JS, Flatten KS, Kaufmann SH, Hiasa H, Xing C and Ferguson DM: On the role of topoisomerase I in mediating the cytotoxicity of 9-aminoacridine-based anticancer agents. Bioorg Med Chem Lett 19: 4459-4462, 2009.

38. Abercrombie $M$ and Ambrose EJ: The surface properties of cancer cells: A review. Cancer Res 22: 525-548, 1962.

39. Carter HB and Coffey DS: Cell surface charge in predicting metastatic potential of aspirated cells from the Dunning rat prostatic adenocarcinoma model. J Urol 140: 173-175, 1988

40. Mehrishi JN: Molecular aspects of the mammalian cell surface. In: Progress in Biophysics and Molecular Biology. Butler JAV and Noble D (eds). Pergamon Press, Oxford, pp3-70, 1972. 
41. Mehrishi JN and Bauer J: Electrophoresis of cells and the biological relevance of surface charge. Electrophoresis 23: 1984-1994, 2002.

42. Korohoda W and Wilk A: Cell electrophoresis-a method for cell separation and research into cell surface properties. Cell Mol Biol Lett 13: 312-326, 2008.

43. Searle GF and Barber J: The involvement of the electrical double layer in the quenching of 9-aminoacridine fluorescence by negatively charged surfaces. Biochim Biophys Acta 502: 309-320, 1978.
44. Doyle GM and Mohler JL: Prediction of metastatic potential of aspirated cells from the Dunning R-3327 prostatic carcinoma model. J Urol 147: 756-759, 1992.

45. Wyckoff JB, Segall JE and Condeelis JS: The collection of the motile population of cells from a living tumor. Cancer Res 60: 5401-5404, 2000.

46. Preet R, Mohapatra P, Mohanty S, Sahu SK, Choudhuri T, Wyatt MD and Kundu CN: Quinacrine has anticancer activity in breast cancer cells through inhibition of topoisomerase activity. Int J Cancer 130: 1660-1670, 2012. 